\title{
Recommendations for the diagnosis of paroxysmal nocturnal hemoglobinuria: a German-Austrian Consensus ${ }^{1)}$
}

\author{
Hubert Schrezenmeier, ${ }^{1, *}$, Peter Bettelheim ${ }^{2}$, \\ Jens Panse ${ }^{3}$, Jörg Schubert ${ }^{4}$, Britta Höchsmann', \\ Alexander Röth ${ }^{5}$ and Thomas Nebe ${ }^{6}$ \\ ${ }^{1}$ Institut für Klinische Transfusionsmedizin und \\ Immungenetik Ulm, DRK Blutspendedienst \\ Baden-Württemberg, Hessen und Institut für \\ Transfusionsmedizin, Universität Ulm, Ulm, Germany \\ ${ }^{2}$ Hämatologie mit Stammzelltransplantation, \\ Hämostaseologie und medizinische Onkologie, \\ Krankenhaus der Elisabethinen Linz, Linz, Austria \\ ${ }^{3}$ Medizinische Klinik IV, Hämatologie und Onkologie, \\ Universitätsklinikum Aachen, Aachen, Germany \\ ${ }^{4}$ Abteilung Hämatologie/Onkologie, Evangelisches \\ Krankenhaus Hamm gGmbH, Hamm, Germany \\ ${ }^{5}$ Klinik für Hämatologie, Westdeutsches Tumorzentrum, \\ Universitätsklinikum Essen, Essen, Germany \\ ${ }^{6}$ Hämatologisches Speziallabor, MVZ Onkologikum \\ Frankfurt am Main, Frankfurt/Main, Germany
}

\begin{abstract}
Paroxysmal nocturnal hemoglobinuria $(\mathrm{PNH})$ is a rare, lifethreatening hematological disease. An acquired mutation in the $P I G-A$ gene in hematopoietic precursor cells leads to a deficiency of glycosylphosphatidylinositol (GPI), a common membrane anchor for certain cell surface proteins. The consequence is a deficiency of the decay-accelerating factor (recognized by antibodies of the cluster CD55) and of the membrane inhibitor of reactive lysis (MIRL, recognized by CD59 antibodies) on the surface of blood cells leading to dysregulation of the complement cascade resulting in characteristic intravascular hemolysis and thromboembolic complications. The analysis of GPI-anchored proteins on blood cells is the recognized diagnostic gold standard. Some aspects
\end{abstract}

\footnotetext{
${ }^{1)}$ Original German online version at: http://www.degruyter.com/ view/j/labm.2011.35.issue-6/j1m.2011.060/jlm.2011.060. $\mathrm{xml}$ ?format=INT. The German article was translated by Compuscript Ltd. and authorized by the authors.

*Correspondence: Prof. Dr. med. Hubert Schrezenmeier, Institut für Klinische Transfusionsmedizin und Immungenetik Ulm, DRK Blutspendedienst Baden-Württemberg, Hessen und Universität Ulm, Helmholtzstrasse 10, 89081 Ulm, Germany

Tel.: +0731-150-550

Fax: +0731-150-500

E-Mail: h.schrezenmeier@blutspende.de
}

of the recently published international guidelines are still a matter of discussion. On the basis of these guidelines, we discussed practical recommendations, which led to the GermanAustrian consensus paper presented here. It contains specific proposals for indication of the test, preanalytical aspects, how to perform immunophenotyping, and for result interpretation. We propose a two-step diagnostic approach. Step 1 is a screening and step 2 is a confirmation of the diagnosis. The latter should be restricted to expert laboratories' experience with PNH. According to this algorithm for a stepwise diagnostic approach, we recommend which antibody panel should be used in which step. The most frequent sources of error and how to avoid them are also summarized. This consensus should support medical laboratories to make an early and correct diagnosis of what is important to therapy and prognosis of the patient. Aspects of economic efficiency and feasibility were also included in our considerations.

Keywords: flow cytometry; German-Austrian consensus; GPI-anchored proteins; immunophenotyping; paroxysmal nocturnal hemoglobinuria; stepwise diagnosis.

\section{Introduction to paroxysmal nocturnal hemoglobinuria}

\section{Definition, pathophysiology, and therapy}

Paroxysmal nocturnal hemoglobinuria $(\mathrm{PNH})$ is a rare progressive, life-threatening blood disease. The estimated incidence is 1.3 new cases per 1,000,000/year; the prevalence of PNH is 5.5 to $15.9: 1,000,000[1,2]$. PNH can occur in patients of any age; the average age at diagnosis is early 30 s [3]. The survival time from diagnosis is, according to older studies (before the introduction of eculizumab), 10-22 years [4, 5]; almost $25 \%$ of patients died within 10 years after diagnosis [5]. Acquired mutations in the $P I G-A$ gene of one or a few hematopoietic progenitor cells are the pathogenetic basis of PNH. This gene is localized on the $\mathrm{X}$ chromosome and encodes the synthesis of the glycosylphosphatidylinositol (GPI). GPI serves as an anchor for many surface proteins, including the complement regulatory proteins CD55 [decay-accelerating factor (DAF)] and CD59 [membrane inhibitor of reactive hemolysis (MIRL)]. Mutations in the $P I G-A$ gene lead to a reduced or complete lack of GPI synthesis and, thus, an absence of this anchor [6-10]. This leads to a partial or complete lack of CD55 and CD59 on the surface of blood cells (leukocytes, thrombocytes and, in 
particular, erythrocytes). The concomitant lack of complement regulation causes the characteristic intravascular hemolysis of the disease [7,11-13]. PNH is characterized by the clinical triad of hemolytic anemia, thrombophilic diathesis, and hematopoietic insufficiency. The incidence of thromboembolic events (including with unusual localization, such as hepatic veins, e.g., Budd-Chiari syndrome) is, next to intravascular hemolysis, another key symptom of PNH. The disease is clinically diverse. It can occur in isolation or in combination with other changes in the bone marrow, such as aplastic anemia (AA), myelodysplastic syndrome at the stage of refractory anemia (RA-MDS) [12], or osteomyelofibrosis (OMF). According to current studies, PNH cells are found, when using highly-sensitive detection methods, in up to $70 \%$ of AA patients and in up to $55 \%$ of MDS patients [14].

For the treatment of PNH up to 2007, there were only non-specific measures, such as blood transfusions, corticosteroids, anticoagulants, folic acid, and iron. Allogeneic stem cell transplantation is indeed the only curative treatment option of $\mathrm{PNH}$, but it is associated with high mortality and morbidity: The 2-year mortality with an HLA-identical donor is up to $44 \%[12,15]$. The only targeted therapy available to patients today is the complement inhibition with eculizumab $\left(\right.$ Soliris $\left.^{\circledR}\right)$, which was approved in Europe in June 2007 [6, 16-19]. Eculizumab is a humanized monoclonal antibody that binds to the complement factor $\mathrm{C} 5$. It thus prevents the latter's split into the fragments $\mathrm{C} 5 \mathrm{a}$ and $\mathrm{C} 5 \mathrm{~b}$ and blocks the formation of the terminal complement complex C5b $[2,20]$. As the treatment with eculizumab blocks a part of the nonspecific immune defense, the patient will have an increased risk of infection, mainly meningococcal disease. Therefore, all patients must be vaccinated before starting eculizumab therapy with a tetravalent conjugate vaccine.

\section{PNH diagnosis}

The diagnosis of PNH is often difficult because the initial symptoms can vary greatly, and hemoglobinuria may not necessarily be present $[4,5,21]$. The immunophenotyping of GPI-anchored proteins or the GPI anchor itself is today the most sensitive and most meaningful method of detection and thus the gold standard in the diagnosis of PNH. Compared to other PNH detection methods, it provides quantitatively and qualitatively the best and most reliable information [22, 23]. Other diagnostic tests, such as acid hemolysis (Ham's test), are less sensitive and specific than flow cytometry and only capture the red cells. They are obsolete for both screening and diagnosis now.

Further basic diagnosis of PNH includes a detailed family and personal medical history, a physical examination, and abdominal sonography. Other than GPI flow cytometry, the following laboratory tests should be carried out: differential blood count and reticulocyte count, reticulocyte production index (RPI) [24], LDH, bilirubin (direct and indirect), haptoglobin, direct Coombs test, folic acid, vitamin B12, iron metabolism (ferritin, transferrin, transferrin saturation, reticulocyte hemoglobin, soluble transferrin receptor), renal and liver function parameters. The soluble transferrin receptor is increased mostly due to increased erythropoiesis and thus not easily evaluated [24]. A bone marrow diagnosis with cytology, histology, and cytogenetics is indicated in the case of concurrent cytopenia and suspected PNH in the context of other hematological diseases (especially with AA or myelodysplastic syndrome) [12].

In flow cytometry with specific antibodies against GPIanchored proteins [23], cells whose GPI-anchored surface proteins are completely absent (type III cells) are differentiated from cells with only partial loss (type II cells). The type III cells arise from such PIG-A mutations (usually insertions or deletions with shifting of the reading frame) and lead to a complete loss of function of the gene product [25]. By contrast, PNH type II cells are usually characterized by point mutation with amino acid substitution that causes a reduced, but not completely repealed, activity of the encoded glycosyltransferase [10]. Cells with normal expression of GPIanchored proteins are called type I cells (=normal cells).

Objective of GPI flow cytometry The detection or exclusion of a significant GPI-deficient population may serve different purposes at initial diagnosis and during follow-up:

- Diagnosis or exclusion of PNH or an overlap syndrome of PNH with other disorders of hematopoiesis (always in the overall context of the medical history and clinical examination findings).

- Detection and quantification of GPI-deficient populations as prognostic markers (e.g., risk of thromboembolic complications in connection with $\mathrm{PNH}$, response to immunosuppression in overlap syndromes with AA or MDS) or as a basis for therapy decisions.

- Detection and quantification of GPI-deficient populations for therapy monitoring (e.g., with eculizumab, immunosuppression in case of overlap syndromes, remission control following allogeneic stem cell transplantation).

The first goal of a screening is the detection of a significant population of blood cells with reduced or absent expression of GPI-anchored proteins. If that is the case, a determination will be made as to which hematopoietic cell lines are affected. The extent of the defect is quantified by determining the proportion of GPI-deficient cells or the proportion of PNH types II and III cells in individual cell lines $[4,7,12,26]$. In follow-up examinations of patients with known GPI deficiency, changes in the proportion of GPI-deficient cells and the involvement of the cell lines are to be recorded.

When is a flow cytometry-based diagnosis of PNH considered reliable? The detection of a significant GPIdeficient population, i.e., of PNH cells, is deemed established when the following conditions are met:

- At least two cell lines (such as erythrocytes and granulocytes or granulocytes and reticulocytes) exhibit a significant GPI-deficient population.

- For each cell line, at least two GPI-anchored proteins, or at least one GPI-anchored protein and the GPI anchor itself (by way of FLAER), must be examined (" $2 \times 2$ " rule, i.e., 
at least two cell lines, at least two GPI-anchored markers per cell line).

- The results of these tests must be concordant. Deficiency of a GPI-anchored marker (e.g., CD16, which is not expressed on eosinophilic or circulating precursors) in connection with the normal expression of other GPI-anchored proteins (such as CD24 or CD66b) suggests an analytic problem circulating progenitor cells or an isolated defect in a protein, but not a GPI anchor deficiency in terms of PNH [12, 22, 27].

The flow cytometric detection of GPI-deficient cells is indeed a central diagnostic tool, but is never used exclusively for the diagnosis of PNH. This essential laboratory result must always be incorporated into an overall assessment, including a medical history, clinical presentation, and other laboratory findings.

\section{Need for standardized recommendations, two-stage diagnostics, and target groups [22]}

A correct proof of GPI-deficient cells is essential for optimal patient management. Because of the rarity of the disease, few laboratories perform regular check-ups, so that the approaches for detecting GPI-deficient clones have so far differed substantially in some cases. This is reflected also in the fact that the literature published on this issue, so far, does not contain any uniform recommendation on the methodology. In order to develop standardized guidelines for the diagnosis of PNH and to improve it in this sense, it is absolutely necessary to adapt the diagnostic recommendations to the ICCS guidelines. These recommendations will be summarized in this overview.

\section{Analytical methods}

Analyses on the diagnosis of PNH and high-sensitivity analyses differ in terms of sensitivity. High-sensitivity analyses can detect very small GPI-deficient populations $(0.01 \%$ or smaller) and are currently subject to research. The following sections, therefore, focus primarily on analyses of the diagnosis and follow-up, by means of which a proportion of GPIdeficient erythrocytes or granulocytes under $1 \%$ should still be detectable.

To serve as a PNH screening test, a diagnostic method must be capable of detecting both patients with large GPI-deficient populations, which are usually associated with hemolytic and/ or thrombotic PNH, and those with very small GPI-deficient populations, e.g., in the context of AA and other bone marrow failures. Diagnostic methods have been described in the literature several times. They require good standards and regular quality controls. To improve and simplify the diagnosis, the implementation of two-step diagnostic testing is recommended (consensus, see chapter on Preanalysis).

\section{Which patients should be tested for PNH?}

$\mathrm{PNH}$, due to non-specific symptoms, is often not diagnosed or with a great delay. Following the recommendations of the
ICSS guidelines for the evaluation of patients with $\mathrm{PNH}$, a $\mathrm{PNH}$ diagnostic test is therefore useful in connection with the following indications [12, 22, 27]:

1. Acquired Coombs-negative hemolytic anemia (with no signs of microangiopathic hemolysis)

2. Intravascular hemolysis with hemoglobinuria/hemosiderinuria and elevated free plasma hemoglobin

3. Signs of an unexplained hemolysis in the presence of

- iron deficiency or

- abdominal pain, dysphagia or

- thrombosis or

- granulocytopenia and/or thrombocytopenia

4. Thrombosis when at least one of the following criteria is met:

- “Atypical” localization

- Hepatic veins (Budd-Chiari syndrome)

- Other abdominal veins (portal vein, splenic vein, visceral veins)

- Cerebral sinus

- Dermal veins

5. Thrombosis (regardless of its location) with signs of concomitant hemolysis

6. Thrombosis (regardless of its location) with unexplained cytopenia

7. Thrombosis (regardless of its location) without known risk factors

8. Presence of bone marrow failure

- Suspicion or evidence of AA

- Suspicion or evidence of myelodysplastic syndrome (refractory anemia, refractory anemia with multilinear dysplasia).

- Other bone marrow disorders (e.g., chronic myeloproliferative syndromes) with concurrent hemolysis

- Other cytopenias of unknown cause after an appropriate diagnostic procedure.

Common clinical symptoms at diagnosis are listed in Table 1.

The prognostic and therapeutic implications require the earliest possible and an unambiguous diagnosis [22]. Therefore, the ICCS guidelines for PNH and the International PNH Interest Group (IPIG) recommend continuous monitoring of patients who have a high risk of $\mathrm{PNH}$ $[12,22]$.

Table 1 Common clinical symptoms at diagnosis.

\begin{tabular}{ll}
\hline Symptoms & Frequency, \% \\
\hline Anemia & up to 100\% [5] \\
Fatigue, impaired quality of life & $96 \%[28]$ \\
Dyspnea & $66 \%[28]$ \\
Chronic renal failure (stage 1-5) & $65 \%[29]$ \\
Abdominal pain & $57 \%[28]$ \\
Erectile dysfunction & $47 \%[28]$ \\
Dysphagia & $41 \%[28]$ \\
Thrombosis & $39 \%[4]$ \\
Hemoglobinuria & $26 \%[30]$ \\
\hline
\end{tabular}




\section{Frequency of checkups}

For patients with a reliable PNH diagnosis, the size of the PNH clone should be checked at regular intervals [22]. During the first 2 years after a diagnosis, a flow cytometric analysis should be carried out every 6 months, and then, if the PNH clone is stable, every year. Any changes to the clinical and hematological parameters, however, require an individual adjustment of the examination intervals. This applies to deteriorations and improvements in the condition because changes in the clone size allow for conclusions about the changed clinical picture in both directions. In patients who receive treatment with eculizumab, regular checks are most helpful in order to demonstrate the stabilization of the erythrocyte clone. If such evidence is provided, the investigation should be carried out at yearly intervals or at the changing of the clinical symptoms or therapy. After an allogeneic stem cell transplantation, we recommend regular flow cytometric analyses (about every 3 months) until the GPI-deficient population is no longer detectable. After that, annual remission checks are recommended.

In addition, regular checkups (at diagnosis and then once a year, or if signs of hemolysis are present) are important for the following patients:

- Patients with AA with small clones that can develop a clinically relevant PNH

- Patients with myelodysplastic syndrome (refractory anemia, refractory anemia with multilinear dysplasia).

Patients treated with eculizumab may produce a positive antiglobulin test, which is due to a C3d-loading of erythrocytes [31,32]. The classification often used for PNH as "Coombs-negative hemolytic anemia" is thus no longer applicable for follow-up examinations during treatment with eculizumab [33].

\section{Recommendations for flow cytometric analysis}

\section{General information}

In advance, the following must be clarified:

- Submission information: The laboratory contracted should be given the following information on a request form accompanying the sample sent in: clinical symptoms and laboratory findings that justify the suspicion of PNH (hemoglobinuria, hemolysis parameters, antiglobulin test, thromboembolic events, iron deficiency of unknown origin), current clinical diagnosis of the patient, preexisting conditions with increased PNH risk (AA, myelodysplastic syndrome of subtype RA), past transfusion (if yes, number and timing of transfusions in the past 3 months). In case of follow-up examinations, especially information regarding current treatment must be shared (particularly eculizumab treatment, including when it was started). For checkups after immunosuppression or stem cell transplantation, the type of treatment and time frame must be stated.

- Information on blood transfusions carried out prior to the taking of a blood sample because they can distort the result.
- Test material: Peripheral blood (preferably EDTAanticoagulated). Bone marrow is not suitable for routine diagnostics because hematopoietic progenitor cells of various differentiation stages express GPI-anchored proteins to varying degrees, thus making the interpretation very difficult.

- Sample volumes: One milliliter is the minimum, $3 \mathrm{~mL}$ is suitable for most tests. If the number of leukocytes is very low, a larger sample size may be necessary [22, 27, 34].

- Anticoagulant: EDTA as an anticoagulant of choice is generally accepted [22, 27, 34]. Contrary to the current international guidelines, we advise against the use of heparin as an anticoagulant, as it can lead to platelet aggregation. As a result, during the measurement process, granulocytes may be overlapped by platelets, giving rise to the risk of false readings. Often, there may also be an agglutination of platelets with monocytes and granulocytes [34].

- Sample shipment: seasonal protection from heat/cold.

- Where possible, samples should not be older than $48 \mathrm{~h}$ (concerning the analysis of leukocytes): The maximum sample age for analyzing erythrocytes is 7 days, but here, too, an attempt should be made to keep the age to no more than $48 \mathrm{~h}$ [22].

\section{Preanalysis}

\section{Cooling the sample}

After $24 \mathrm{~h}$, the sample must be stored at $4^{\circ} \mathrm{C}$ [22].

\section{Lysis reagent}

Before the leukocyte analysis, the red cells must be lysed. All commercial reagents can be used for this. However, it should be mentioned that there is no comprehensive comparison of commercially available reagents. As an alternative, ammonium chloride is recommended. When using ammonium chloride, however, it must be noted, based on our experience, that it leads to a selective loss of granulocytes (particularly in aging granulocytes) and thus false readings. As well, ammonium chloride is not stable over a long period of time [34].

\section{Flow cytometry}

We recommend a two-stage diagnosis of PNH: In the screening phase, if there is a suspicion of PNH, the analysis of erythrocytes and/or reticulocytes and neutrophils is carried out by way of a small antibody panel $(2 \times 2$ rule, i.e., two cell lines with at least two markers each). If the screening produces a pathological finding, the marker panel will be expanded to include further cell lines (monocytes, lymphocytes, possibly platelets). Such an extended diagnosis aims to confirm a PNH diagnosis and describes precisely the affected cell lines.

\section{Cell labeling}

Leukocytes When analyzing leukocytes, a non-GPIanchored marker should always be used in addition to the GPI-anchored proteins in order to identify the respective cell 
type (e.g., CD11b for granulocytes, CD33 for monocytes, CD3 and CD19 for T and B lymphocytes). For each cell line, at least two GPI-anchored proteins must be examined, and each approach must include suitable isotype controls.

As a matter of principle, the PNH diagnosis must include neutrophils, especially as significant erythrocyte clones have never been observed in the absence of PNH clones of neutrophils [35]. In patients with very severe AA, severe neutropenia and reticulocytopenia may require that the analysis of the neutrophils, and possibly of the reticulocytes, be dispensed with [34]. In the event, however, the test of these cell lines should be made up, with hematopoietic reconstitution, after the treatment.

\section{Sample preparation for leukocyte testing}

EDTA blood is incubated with the appropriate antibody. After a 15- to 30-min incubation at room temperature in the dark, it is washed, and the lysing reagent is added. A further incubation period is followed by multiple washing steps $[27,36]$.

\section{Choice of antibody for neutrophil testing (Table 2) - screening phase}

For the analysis of neutrophil granulocytes, most experience involves CD16, CD24, and CD66b. When using CD16, it is important to note that CD16 is missing from the eosinophils and that in patients with myelodysplastic syndrome, it may also be absent from granulocytes. Furthermore, there are polymorphic variants of CD16 that are not recognized by some CD16 antibodies. Therefore, CD16 should not be the sole marker [4]. To simplify the methodology upon obtaining a high specificity, it is also possible to combine a fluorochromelabeled antibody against various GPI-anchored proteins (such as CD24 and CD66b) with a different antibody, labeled with another fluorochrome (e.g., CD24-fluorescein isothiocyanate (FITC)/CD66b-FITC and CD16-PE). In case of a GPI-anchor defect, all GPI-anchored markers must be affected.

Generally, the chosen fluorochrome conjugates and antigen density must allow for a clear separation of positive and negative cells (so-called bimodal distribution), which is not always the case, especially with FITC or peridinin-chlorophyll-protein
A (PerCP). Appropriate washing steps before and after labeling and the exclusion of dead cells increase the sensitivity of detection, especially in the range of about $1 \%$ GPI-deficient cells.

\section{Choice of antibody for leukocyte testing - advanced diagnostics (Table 2)}

For the detection of monocyte clones, CD14 and CD48 are recommended. CD55 can also be used for the analysis of monocytes [39]. CD48 and CD52 can be used to test lymphocytes [36]. A special marker for the GPI anchor is fluorescently labeled aerolysin (FLAER). FLAER binds directly to the GPI anchor. It is suitable for the analysis of granulocytes and monocytes. With FLAER, one observes a variability of the batches. We therefore recommend FLAER only in combination with antibodies to GPI-anchored proteins. As a "stand-alone reagent" it offers no advantage and is also only available from one manufacturer [34].

\section{Erythrocytes/reticulocytes - screening phase}

The sole measurement of red blood cells is not sufficient for the diagnosis of PNH. With hemolysis and transfusions, the PNH clone may be underestimated, which can result in false-negative results. The testing of reticulocytes has a higher sensitivity, as they are less affected by acute hemolysis or transfusions, and therefore, the proportion of GPI-deficient reticulocytes in most cases is greater than the proportion of GPI-deficient erythrocytes [36]. In addition, GPI-deficient reticulocytes correlate better with GPI-deficient neutrophils [36]. The differentiation of erythrocytes and reticulocytes is done by means of RNA dyes, which are suitable for flow cytometry, or with an antibody against the transferrin receptor (CD71).

\section{Sample preparation for erythrocyte testing}

A diluted whole blood sample, washed twice with buffer, is incubated with the selected antibody for 15-20 min at room temperature. The incubation period is followed by a washout period. For the analysis of reticulocytes, the sample is incubated with thiazole orange or a Reticount ${ }^{\mathrm{TM}}$ solution (Becton

Table 2 Antibody selection and analysis strategy in the flow cytometric diagnosis of PNH.

\begin{tabular}{|c|c|c|}
\hline Target cells & Reagents [29, 32] & $\begin{array}{l}\text { Gating strategies (combination of cell line-specific markers and/or scattered } \\
\text { light) }[23,37]\end{array}$ \\
\hline Granulocytes & $\begin{array}{l}\text { CD16 }^{\mathrm{a}} \text {, CD24, CD55, } \\
\text { CD66b, FLAER }^{\mathrm{b}}\end{array}$ & $\begin{array}{l}\text { CD15 and side-scattered light, CD45 and side-scattered light, CD11b and } \\
\text { side-scattered light }\end{array}$ \\
\hline Monocytes & $\begin{array}{l}\text { CD14, CD48, CD55, } \\
\text { FLAER }\end{array}$ & $\begin{array}{l}\text { CD33 and side-scattered light, CD } 45 \text { and side-scattered light }[27,38] \text {, pos- } \\
\text { sibly CD64 as well, if monocytes are difficult to separate }\end{array}$ \\
\hline Erythrocytes/reticulocytes ${ }^{c}$ & CD58, CD59, (CD55) & Forward- and side-scattered light, glycophorin A (CD235a) \\
\hline
\end{tabular}

${ }^{a}$ Do not use anti-CD16 as the sole marker: There are polymorphic variants of CD16 and CD16 that are absent from eosinophils or immature progenitor cells (left shift). CD14 and CD16 are clusters of monoclonal antibodies to maturation-dependent differentiation antigens. ${ }^{\mathrm{b}} \mathrm{FLAER}$ binds specifically to the GPI anchor, thus improving the detection of small amounts of PNH cells [12, 23, 41]. 'By testing the reticulocytes instead of the erythrocytes, the question of whether the patient was transfused (thus distorting the testing of allogeneic erythrocytes) before the taking of blood can be ignored. 
Dickinson, Heidelberg, Germany). The pretreated samples should then be analyzed within $2 \mathrm{~h}$ [27].

\section{Choice of antibody for erythrocyte testing - screening phase (Table 2)}

In order to confirm the diagnosis of $\mathrm{PNH}$, proof of the deficiency of GPI-anchored proteins with at least two antibodies is required. Here, the general consensus calls for CD59 antibodies in connection with erythrocytes. The use of CD58 antibodies is considered to be problematic according to the guidelines, as CD58 is expressed on the erythrocytes both as a GPI-anchored antigen and a transmembrane form. This can lead to difficulties in interpreting the test results $[40,41]$. In our experience, however, a very good correlation exists between the expressions of the GPI anchor determined by the CD58 and CD59 antibodies [36]. There are congenital CD55 deficiencies, and CD55 is generally less strongly expressed on red blood cells than CD59, making the differentiation of erythrocytes with reduced expression and cells with normal expression more difficult. CD55 is therefore not recommended as the sole antibody. We therefore recommend primarily the use of CD59 and CD58 as a second, or CD55 as a third, choice, thus resulting in our recommendation that CD58 and CD59 should be used in the screening phase [27, 36].

\section{Choice of antibody for erythrocyte testing - advanced diagnostics (Table 2)}

To confirm findings in the special diagnosis phase, the antibody panel can be expanded to include CD55. If erythrocytes and reticulocytes were not initially tested, it is advisable to examine both as part of the advanced diagnostics [27, 36].

\section{Analysis phase}

\section{Leukocytes: cell acquisition and gating (Table 2)}

For the differentiation of granulocytes and monocytes, the sideward-scattered light is measured in combination with appropriate cell lineage-specific markers.

For tests with the goal of detecting a GPI-deficient population of $1 \%$, the data acquisition of 15,000 cells is sufficient $[22,34]$.

\section{Erythrocytes: cell acquisition and gating (Table 2)}

Erythrocytes can be identified based on their specific light scattering properties. By evaluating the forward- and sideward-scattered light (shown in logarithmic mode), cell debris and significant aggregations can be differentiated from erythrocytes. Erythrocytes and their precursor stages are even clearer to identify by adding antibodies against glycophorin A (CD235a), which as an erythrocyte-specific transmembrane protein allows for a reliable differentiation from leukocytes.

Usually, the acquisition of approximately 15,000 erythrocytes or reticulocytes for an investigation with a detection limit of $1 \%$ is sufficient for PNH diagnostics [22, 34].
As the negative events - i.e., those not reacting with the antibodies (ideally, cells) - are decisive for the diagnosis, any contamination must be removed carefully from the reagents (wash solutions, antibodies, dilution solutions, etc.), as well as debris from the sample and the equipment lines. The use of fluorescent antibodies to non-GPI-anchored membrane proteins for the positive identification of the cell class of interest (e.g., CD15, CD235, CD33) reduces this risk. It is essential to the diagnostics of PNH also for this reason that the person assessing and issuing the results have the measurement printouts available and not only the measurement results in figures (Figures 1 and 2) [34].

\section{High-sensitivity flow cytometry}

The high-sensitivity flow cytometry is not necessary for the diagnosis of classic PNH. It can be helpful for very small GPI-deficient populations ( $0.01 \%$ or less), e.g., in patients with AA [22, 23].

\section{Evaluation}

For quality control purposes, samples suspected of PNH should be tested against normal samples. The simultaneous use of a positive control, i.e., a known PNH sample, would be desirable. As PNH is very rare, most laboratories have no or very few PNH samples available, so it is hardly possible to test each sample for PNH with a positive control. Commercial control material is not currently available [22]. Therefore, it is important that the largest possible number of laboratories participates in the round-robin tests offered by INSTAND e.V. since March 2011. On the other hand, it is recommended that PNH samples, especially in the case of questionable findings (e.g., clinical picture and medical history do not match the detected clone size, or a large discrepancy between the different GPI-markers within the test), be sent to a laboratory specializing in PNH analysis to confirm the findings (Figure 3).

\section{Issuance/documentation of findings}

The diagnosing physician or scientist must have available to him the original printouts of the immunocytometric measurements for his assessment, so that he can check the quality of the sample, the gates, the histograms, and the number of cells tested. On repeated examination, it is advantageous if the printouts of the previous tests are available.

A major future task concerns the standardization of the result documentation. This serves to simplify the diagnosis, but it is especially important to avoid misunderstandings in the communication between diagnostic laboratories and physicians - an aspect that is very important in connection with the rare disease PNH. Patients often seek out, in addition to local physicians, regional expert centers for a second or third opinion. Practical experience shows that often results are communicated where it is not clear whether the percentages are based on the normal or GPI-deficient cells and on which cell line a quantitative indication of the "clone size" is based, and how sensitive the method used was. 
A
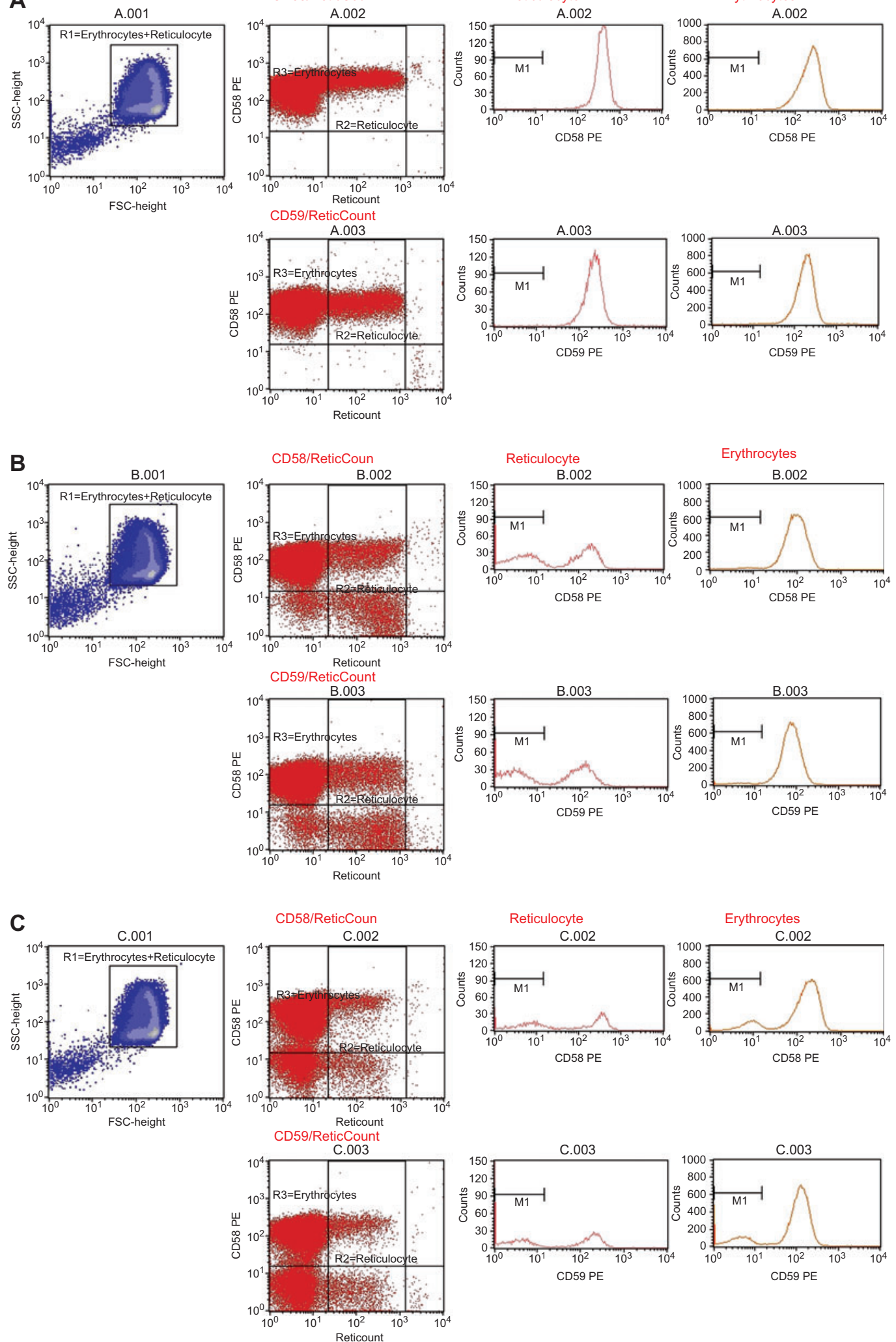

Figure 1 Testing the expression of CD58 and CD59 on erythrocytes (column 4) and reticulocytes (column 3), which are discriminated by way of thiazole orange (column 2).

(A) shows a healthy control person. (B) shows a patient with PNH in the context of another hematologic disease. The proportion of GPIdeficient reticulocytes and red blood cells is $41 \%$ or $1.2 \%$. (C) shows a patient with classic hemolytic PNH. The proportion of GPI-deficient reticulocytes and red blood cells is $47 \%$ or $16 \%$. 

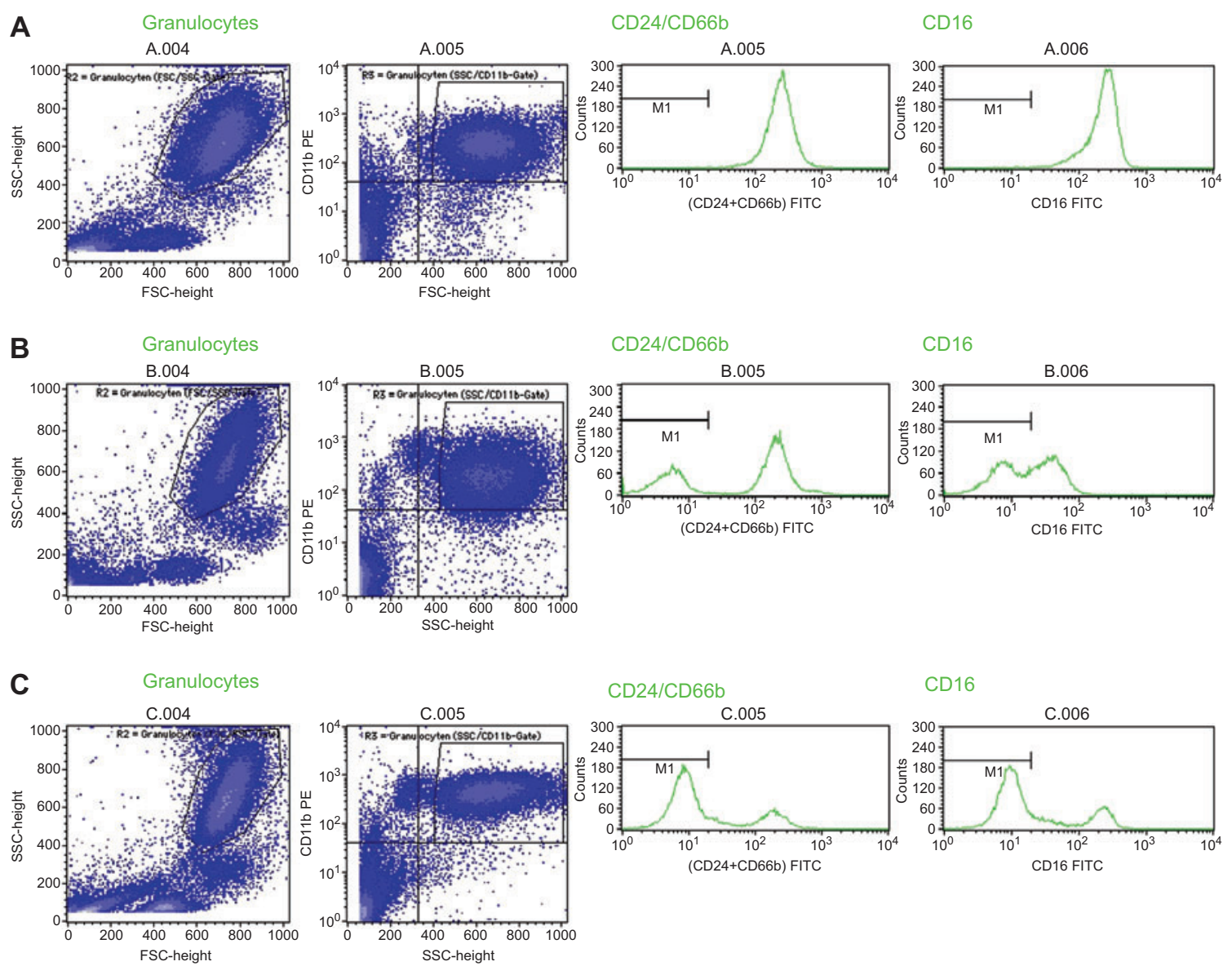

Figure 2 Testing of the expression of CD24, CD66b, and CD16 on neutrophils.

(A) shows a healthy control person. (B) shows a patient with PNH in the context of another hematologic disease. The proportion of GPIdeficient granulocytes is 15\%. (C) shows a patient with classic hemolytic PNH. The proportion of GPI-deficient neutrophils is $66 \%$.

In this sense, the measured result should always be stated in the context of other hematologic findings and consider the following aspects:

- Full blood count: Hb, erythrocytes, MCV, MCH, RDW, platelets

- Reticulocytes: percentage and absolute number; reticulocyte production index (RPI)

- PNH clone size (percentage of deficient cells, i.e., always specify the pathological cells with reduced/absent expression), indicating which cell lines were tested

- Distribution of type II and III cells, indicating which cell lines are affected

- Information on which non-GPI-anchored markers were used to identify the examined cell lines

- Sensitivity level (percentage of GPI-deficient cells that can be detected reliably). As this information differs for each GPI-anchored protein and the individual cell lines, this information is required for each marker and cell line.

- Information on preliminary tests (date and their results).

If in one patient a normal expression of GPI-anchored proteins is detected, this should be expressed in as simple and clear language as possible: "Granulocytes, monocytes, and erythrocytes show a normal expression of GPI-anchored proteins. There were no detected PNH clones." Caution should be exercised with negative or positive terminology (e.g., "The PNH test was negative" or "All cells are positive"), as these can easily lead to misinterpretations.

\section{Interference and troubleshooting}

Interference distorting the outcome can occur both in the preparatory phase and in the actual analysis phase. Each laboratory should determine, as part of the validation of the PNH diagnostics, its own sensitivity limit, i.e., to know the background signal of negative events concerning the reaction with the corresponding fluorescent antibodies. Untreated, this can often be in the range of $0.5 \%-2 \%$, depending on the contamination of the antibody preparation, the equipment, the wash solutions, or the sheath fluid, i.e., in the range of the desired detection limit of the PNH clone.

Common sources of error and recommendations for problem resolution are summarized in Table 3. 


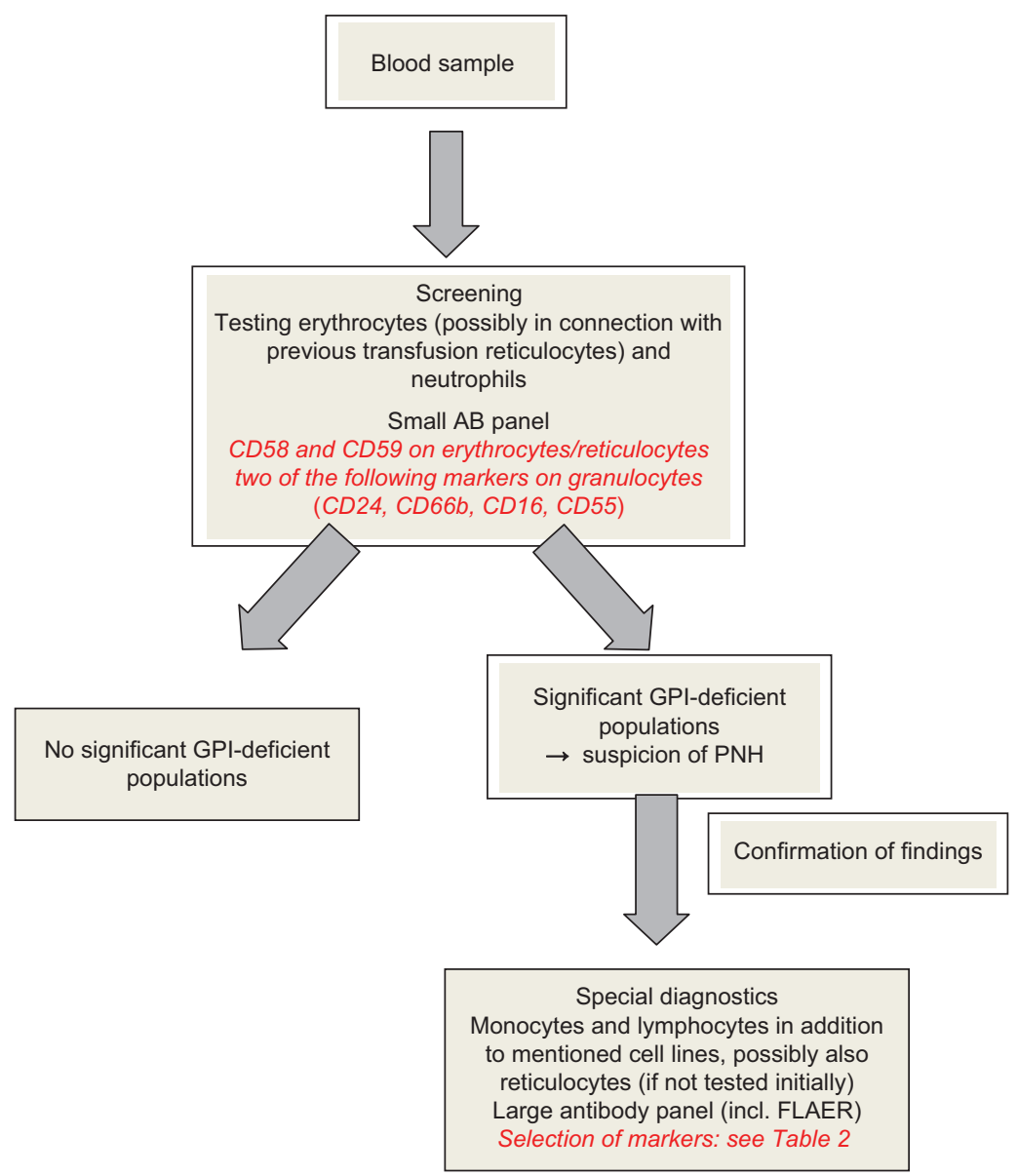

Figure 3 Algorithm staged diagnostics for suspected PNH.

Table 3 Potential errors and recommendations for problem correction in flow cytometric PNH diagnosis.

\begin{tabular}{|c|c|c|}
\hline Cause & Impact & Troubleshooting \\
\hline Bone marrow aspirate as a material & $\begin{array}{l}\text { Expression of GPI-anchored markers changes } \\
\text { during differentiation; no established } \\
\text { diagnostic cutoffs for proportion of } \\
\text { GPI-deficient cells }\end{array}$ & $\begin{array}{l}\text { Inform sender; request new sample (peripheral } \\
\text { blood) }\end{array}$ \\
\hline $\begin{array}{l}\text { Sample too old; sample exposed to } \\
\text { extreme climatic conditions (heat, } \\
\text { cold) }\end{array}$ & $\begin{array}{l}\text { Hemolysis, apoptosis, alteration of the surface } \\
\text { proteins }\end{array}$ & $\begin{array}{l}\text { Viability determination } \\
\text { In case of "suspicion", inquire about sample- } \\
\text { taking time; order new sample if necessary }\end{array}$ \\
\hline Transfusions before blood taking & $\begin{array}{l}\text { High proportion of donor red cells, no } \\
\text { meaningful analysis possible of patient } \\
\text { erythrocytes }\end{array}$ & $\begin{array}{l}\text { Analysis of reticulocytes rather than } \\
\text { erythrocytes }\end{array}$ \\
\hline Use of heparin as an anticoagulant & $\begin{array}{l}\text { Risk of platelet aggregation: } \rightarrow \text { superposition } \\
\text { of granulocytes during measurement } \rightarrow \text { "stick" } \\
\text { on monocytes or granulocytes }\end{array}$ & Using EDTA as an anticoagulant \\
\hline $\begin{array}{l}\text { Using ammonium chloride as lysis } \\
\text { reagent }\end{array}$ & $\begin{array}{l}\text { Can lead to loss of granulocytes (especially } \\
\text { older cells) }\end{array}$ & $\begin{array}{l}\text { Using commercial reagents (FACS Lysing } \\
\text { Solution) }\end{array}$ \\
\hline $\begin{array}{l}\text { Main source of error: Contamination } \\
\text { of the analysis gate with unwanted } \\
\text { cells, such as: } \\
\text { - Eosinophils or progenitor cells in } \\
\text { the neutrophil gate } \\
\text { - Leukocytes in the erythrocyte gate }\end{array}$ & $\begin{array}{l}\text { Do not express CD16 or CD24 } \rightarrow \text { can lead to } \\
\text { misinterpretation as GPI-deficient neutrophils } \\
\text { Misinterpreted as GPI-deficient erythrocytes }\end{array}$ & $\begin{array}{l}\text { - Using cell line-specific markers (see Table 2) } \\
\text { - Do not use anti-CD16 as the sole marker } \\
\text { - Verifying analysis of CD16, CD24, CD55, or } \\
\text { CD59 with FLAER } \\
\text { Use of anti-glycophorin A (CD235a) }\end{array}$ \\
\hline
\end{tabular}




\section{Clinical implications of laboratory findings}

\section{No confirmation of suspected PNH - further steps}

If the PNH suspicion could not be confirmed, the following options should be reconsidered: If measurement errors or misinterpretations can be excluded (check, if necessary, repeat measurement), the clinical symptoms that justify the suspicion of PNH must be clarified further via differential diagnoses. If it involves the blood sample of a patient with a known underlying disease, however, that is associated with an increased risk of PNH, (e.g., AA, RAMDS), the examination should be repeated at regular intervals.

Implausible results where there are discrepancies between the results of the two antibodies in two cell lines should be clarified by a second laboratory with experience in the diagnosis of PNH. The laboratory should be able to clarify the possible differential diagnoses (red cell fragmentation syndrome, spherocytosis, etc.). This requires, at a minimum, the microscopic evaluation of the blood smear.

\section{Evidence of PNH - further steps}

If PNH has been detected beyond doubt, i.e., the finding was confirmed in diagnostic step 2 (advanced diagnostics), an overall concept must be prepared without delay for the further care. This includes, apart from non-specific measures, such as blood transfusions, the administration of corticosteroids, anticoagulants, folic acid, and iron, the decision whether a specific therapy is indicated. On the one hand, this is the targeted treatment involving the complement inhibitor eculizumab, which was approved in 2007. On the other hand, the indication for an allogeneic stem cell transplantation must be checked, the only curative treatment option, which is, however, associated with high morbidity and mortality. Depending on the chosen procedure, the scope and frequency of followup examinations are defined as well. Finally, the impact of the diagnosis and possible treatment on the patient's life circumstances must be taken into account. As PNH is a rare disease, and complex aspects must be considered, it is recommended, to confirm the diagnosis and treatment concept, that an expert center be contacted. Recommendations on the therapeutic approach in connection with PNH can be found at www.onkopedia.de [42].

The PNH Registry is an international, multicenter, noninterventional observational study of PNH - independent of the treatment. The aim of the registry is to learn more about this rare disease, its long-term progression, prognostic factors, and the effects of various therapeutic interventions. Patients should be informed about this registry and invited to participate. Detailed information can be obtained through the National Coordinator in Germany (H. Schrezenmeier) and Austria (P. Bettelheim).

\section{Discussion}

Flow cytometry is now a widely established diagnostic method. It is the recognized gold standard, especially with respect to $\mathrm{PNH}$ diagnostics and ongoing monitoring. Yet, so far, there are no standardized recommendations on how the sample handling is to take place in the preparatory and analysis phases and how a sensible division of the diagnosis into a screening phase and advanced diagnostics to confirm the findings can be realized. The international guidelines, which have been published in the meantime, also continue to leave these questions up for debate. Therefore, the expert panel has made it its mission to use this present study, which is based on the new guidelines, to close the gap and to bring about a German-Austrian consensus.

It was important to give recommendations to enable a correct and early diagnosis that is relevant for PNH patients in terms of treatment and prognosis. One should not lose sight of the laboratory reality, thus resulting in the proposal of the described two-stage diagnostics in terms of practicality and efficiency. Step 2 in the diagnostics, which is about confirming findings, can be performed only by few specialized laboratories. Step 1 is the screening stage, which all laboratories should be able to perform routinely. A key requirement also for laboratories that engage in screening-stage PNH diagnostics - is regular participation in round-robin tests. For the purposes of quality assurance, therefore, INSTAND e.V. (Society for the Promotion of Quality Assurance in Medical Laboratories) performed the first round-robin test for PNH diagnostics in March 2011. This involved more than 40 laboratories from Germany, Austria, and other countries. The round-robin test will continue to be offered in the future regularly, twice a year.

\section{References}

1. Les Cahiers d'Orphanet; November 2008;1:2-26.

2. Hill A, Ridley SH, Esser D, Oldroyd RG, Cullen MJ, Kareclas P, et al. Protection of erythrocytes from human complement-mediated lysis by membrane-targeted recombinant soluble CD59: a new approach to PNH therapy. Blood 2006;107:2131-7.

3. Socie G, Mary JY, de GA, Rio B, Leporrier M, Rose C, et al. Paroxysmal nocturnal haemoglobinuria: long-term follow-up and prognostic factors. French Society of Haematology. Lancet 1996;348:573-77.

4. Hillmen P, Lewis SM, Bessler M, Luzzatto L, Dacie JV. Natural history of paroxysmal nocturnal hemoglobinuria. N Engl J Med 1995;333:1253-8.

5. de Latour PR, Mary JY, Salanoubat C, Terriou L, Etienne G, Mohty M, et al. Paroxysmal nocturnal hemoglobinuria: natural history of disease subcategories. Blood 2008;112:3099-106.

6. Brodsky RA, Young NS, Antonioli E, Risitano AM, Schrezenmeier $\mathrm{H}$, Schubert J, et al. Multicenter phase 3 study of the complement inhibitor eculizumab for the treatment of patients with paroxysmal nocturnal hemoglobinuria. Blood 2008;111:1840-7.

7. Johnson RJ, Hillmen P. Paroxysmal nocturnal haemoglobinuria: nature's gene therapy? Mol Pathol 2002;55:145-52.

8. Luzzatto L, Gianfaldoni G. Recent advances in biological and clinical aspects of paroxysmal nocturnal hemoglobinuria. Int $\mathrm{J}$ Hematol 2006;84:104-12.

9. Araten DJ, Nafa K, Pakdeesuwan K, Luzzatto L. Clonal populations of hematopoietic cells with paroxysmal nocturnal hemoglobinuria genotype and phenotype are present in normal individuals. Proc Natl Acad Sci USA 1999;96:5209-14. 
10. Bessler M, Mason PJ, Hillmen P, Luzzatto L. Mutations in the PIG-A gene causing partial deficiency of GPI-linked surface proteins (PNH II) in patients with paroxysmal nocturnal haemoglobinuria. Br J Haematol 1994;87:863-6.

11. Rother RP, Bell L, Hillmen P, Gladwin MT. The clinical sequelae of intravascular hemolysis and extracellular plasma hemoglobin: a novel mechanism of human disease. J Am Med Assoc 2005;293:1653-62.

12. Parker C, Omine M, Richards S, Nishimura J, Bessler M, Ware $\mathrm{R}$, et al; for International PNH Interest Group. Diagnosis and management of paroxysmal nocturnal hemoglobinuria. Blood 2005;106:3699-709.

13. Hall SE, Rosse WF. The use of monoclonal antibodies and flow cytometry in the diagnosis of paroxysmal nocturnal hemoglobinuria. Blood 1996;87:5332-40.

14. Galili N. Prevalence of paroxysmal nocturnal hemoglobinuria $(\mathrm{PNH})$ cells in patients with myelodyplastic syndromes (MDS), aplastic anemia (AA) or other bone marrow failure syndromes (BMF): interim results from the EXPLORE trial. J Clin Oncol 2009;27(suppl.):7082.

15. Saso R, Marsh J, Cevreska L, Szer J, Gale RP, Rowlings PA, et al. Bone marrow transplants for paroxysmal nocturnal haemoglobinuria. Br J Haematol 1999;104:392-6.

16. Hillmen P, Young NS, Schubert J, Brodsky RA, Socie G, Muus P, et al. The complement inhibitor eculizumab in paroxysmal nocturnal hemoglobinuria. N Engl J Med 2006;355:1233-43.

17. Hillmen P, Muus P, Duhrsen U, Risitano AM, Schubert J, Luzzatto L, et al. Effect of the complement inhibitor eculizumab on thromboembolism in patients with paroxysmal nocturnal hemoglobinuria. Blood 2007;110:4123-28.

18. Rother RP, Rollins SA, Mojcik CF, Brodsky RA, Bell L. Discovery and development of the complement inhibitor eculizumab for the treatment of paroxysmal nocturnal hemoglobinuria. Nat Biotechnol 2007;25:1256-64.

19. Röth A, Dührsen U, Schrezenmeier H, Schubert J. Paroxysmale nächtliche hämoglobinurie $(\mathrm{PNH})$ - pathogenese, diagnostik und therapie. Dtsch Med Wochenschr 2009;134:404-9.

20. Schrezenmeier H, Höchsmann B. Eculizumab opens a new era of treatment for paroxysmal nocturnal hemoglobinuria. Expert Rev Hematol 2009;2:7-16.

21. Späth-Schwalbe E, Schrezenmeier H, Heimpel H. Paroxysmale nächtliche hämoglobinurie: klinische erfahrungen bei 40 patienten in einem zentrum über 25 jahre. Dtsch Med Wochenschr 1995;120:1027-33.

22. Borowitz M, Craig F, DiGuiseppe J, Illingworth A, Rosse W, Sutherland D, et al. Guidelines for the diagnosis and monitoring of paroxysmal nocturnal hemoglobinuria and related disorders by flow cytometry. Cytometry B Clin Cytom 2010;78B:211-30.

23. Richards SJ, Barnett D. The role of flow cytometry in the diagnosis of paroxysmal nocturnal hemoglobinuria in the clinical laboratory. Clin Lab Med 2007;27:577-90.

24. Röth A, Hock C, Konik A, Christoph S, Dührsen U. Chronic treatment of paroxysmal nocturnal hemoglobinuria patients with eculizumab: safety, efficacy, and unexpected laboratory phenomena. Int J Hematol 2011;93:704-14.

25. Brodsky RA, Hu R. PIG-A mutations in paroxysmal nocturnal hemoglobinuria and in normal hematopoiesis. Leuk Lymphoma 2006;47:1215-21.

26. Maciejewski JP, Rivera C, Kook H, Dunn D, Young NS. Relationship between bone marrow failure syndromes and the presence of glycophosphatidyl inositol-anchored protein-deficient clones. Br J Haematol 2001;115:1015-22.
27. Nebe T, Schubert J, Gutensohn K, Schrezenmeier H. Flow cytometric analysis of GPI-deficient cells for the diagnosis of paroxysmal nocturnal hemoglobinuria (PNH). J Lab Med 2003;27:257-65.

28. Meyers G, Weitz I, Lamy T, Cahn JY, Kroon HA, Severino B, et al. Disease-related symptoms reported across a broad population of patients with Paroxysmal Nocturnal Haemoglobinuria. Blood 2007; 110:Abstract 3683.

29. Hillmen P, Elebute MO, Kelly R, Urbano-Ispizua A, Rother RP, $\mathrm{Fu} C \mathrm{C}$, et al. High incidence of progression to chronic renal insufficiency in patients with paroxysmal nocturnal hemoglobinuria (PNH). Blood 2007;110:Abstract and Poster 3678.

30. Dacie JV, Lewis SM. Paroxysmal nocturnal haemoglobinuria: clinical manifestations, haematology, and nature of the disease. Ser Haematol 1972;5:3-23.

31. Röth A, Peine S, Dührsen U. Paroxysmal nocturnal hemoglobinuria turning Coombs-positive. Int J Hematol 2010;91: 159-60.

32. Höchsmann B, Leichtle R, von Zabern I, Kaiser S, Flegel WA, Schrezenmeier H. Paroxysmal nocturnal hemoglobinuria (PNH) and targeted therapy with the C5 antibody Eculizumab - lessons for transfusion medicine. Vox Sang 2011 Sep 19; [epub ahead of print].

33. Risitano AM, Notaro R, Marando L, Serio B, Ranaldi D, Seneca $\mathrm{E}$, et al. Complement fraction 3 binding on erythrocytes as additional mechanism of disease in paroxysmal nocturnal hemoglobinuria patients treated by eculizumab. Blood 2009;113: 4094-100.

34. Bettelheim P, Nebe C, Panse J, Röth A, Schubert J, Schrezenmeier H. Konsensusmeeting Diagnostik der PNH 24.11.2010 München.

35. Sutherland DR, Kueck N, Azcona-Olivera J, Anderson T, Acton E, Barth D, et al. Use of FLAER-based WBC assay in the primary screening of PNH clones. Am J Clin Pathol 2009;132: 564-72.

36. Höchsmann B, Rojewski M, Schrezenmeier H. Paroxysmal nocturnal hemoglobinuria $(\mathrm{PNH})$ : higher sensitivity and validity in diagnosis and serial monitoring by flow cytometric analysis of reticulocytes. Ann Hematol 2011;90:887-99.

37. Richards SJ, Whitby I, Cullen MJ, Dickinson AJ, Granger V, Reilly JT, et al. Development and evaluation of a stabilized whole-blood preparation as a process control material for screening of paroxysmal nocturnal hemoglobinuria by flow cytometry. Cytometry B Clin Cytom 2008;76:47-55.

38. Sutherland DR, Kuek N, Davidson J, Barth D, Chang H, Yeo E, et al. Diagnosing PNH with FLAER and multiparameter flow cytometry. Cytometry B Clin Cytom 2007;72:167-77.

39. Olteanu H, Karandikar NJ, McKenna RW, Xu Y. Differential usefulness of various markers in the flow cytometric detection of paroxysmal nocturnal hemoglobinuria in blood and bone marrow. Am J Clin Pathol 2006;126:781-78.

40. Ariel O, Kukultansky T, Raz N, Hollander N. Distinct membrane localization and kinase association of the two isoforms CD58. Cell Signal 2004;16:667-73.

41. Navenot JM, Bernard D, Harousseau JL, Muller JY, Blanchard D. Expression of glycosyl-phosphatidylinositol-linked glycoproteins in blood cells from paroxysmal nocturnal haemoglobinuria patients: a flow cytometry study using CD55, CD58 and CD59 monoclonal antibodies. Leuk Lymphoma 1996; 21:143-51.

42. Schubert J, Brümmendorf T, Schrezenmeier H, Röth A. Leitlinie Paroxysmale Nächtliche Hämoglobinurie 2011. http://www.dgho-onkopedia.de/onkopedia/leitlinien/paroxysmale-naechtlichehaemoglobinurie-pnh. Accessed June 13, 2011. 